\title{
Optimism and Well-Being in Hungarian Employees: First Application and Test of a Situational Judgment Approach to Explanatory Style
}

\author{
Eszter Kovács \\ Profil Training, Ltd.
}

\author{
Tamás Martos \\ University of Szeged
}

\begin{abstract}
Research on the explanatory style model of optimistic mindset has burgeoned in the last decades. The present study presents the first examination of a new measure of the optimistic mindset, the MQ Test. The MQ Test uses 36 personal and work situations for prompting responses; however, it applies a situational judgment test approach. In the present study, crosssectional data with 437 Hungarian employees showed low to acceptable level of internal consistency and good test-retest reliability for the subscales. Exploratory and confirmative factor analyses provided evidence for separate sub-dimensions of negative $(\mathrm{N})$ and positive $(\mathrm{P})$ events. Accordingly, a 14 item Short MQ Test version was developed with P and N subscales. Structural equation models showed that $\mathrm{P}$ and $\mathrm{N}$ were differently and positively related to dispositional optimism, hope, self-esteem, self-efficacy and satisfaction with life. The limitations and potential merits of the MQ Test are discussed, along with its potential further development.
\end{abstract}

Key words: explanatory style, test development, situational judgment test, well-being, Hungarian employees

\section{Introduction}

The theory of learned optimism (Seligman, 1991) is among the most intensively studied phenomenon in the science of positive psychological functioning (Peterson \& Steen, 2009). Unlike other theorists, Seligman conceptualized optimism/pessimism as a personal explanatory style (also referred to as attributional style), i.e., a relatively stable mindset to explain the causes of positive and negative events and situations in terms of three interrelated forms (three different dimensions) of possible explanations with regard to their causes. The Stability (S) dimen-

Correspondence concerning this article should be addressed to Tamás Martos, Institute of Psychology, University of Szeged, 6722 Szeged, Hungary. E-mail: martos.m.tamas@gmail.com

Received February 25, 2016 sion refers to the time frame of the causes; whether the actual cause is timely extended, stable vs. unstable. The Globality $(\mathrm{G})$ dimension captures whether the individual sees the actual event as the result of general vs. specific situational factors, i.e. the causes having an effect on other events as well or not. The Internality (I) dimension refers to the role of the individual himself. The internal and external causality attributions place the agency in or outside the person considering the causes of the event.

Based on these distinctions between the three dimensions ( $\mathrm{S}, \mathrm{G}$ and $\mathrm{I}$ ), the explanations as well as the nature of the situation (negative vs. positive), an optimistic mindset can be defined in the following way. For the explanation of negative situations an individual with optimistic explanatory style tends to use external causes along with seeing the situation as particular and temporarily sporadic (e.g., it was caused by somebody else, and it occurred just here and 
now). On the other hand, in case of positive events an optimistic explanatory style would involve internal causality, along with a generalized and temporarily extended view of the situation (it was me, and it can happen elsewhere and at other times as well). Both patterns of optimism were found to be positively related to better mental health, higher self-esteem, lower depression and lower risk of post-traumatic stress disorder (Peterson \& Seligman, 1984; Peterson \& Steen, 2009).

\section{Measurement of Explanatory Styles}

When it comes to measurement of explanatory styles, there are series of methods described in the literature (Proudfoot, Corr, Guest, \& Gray, 2001). First, patterns of different explanation types for previous events may be coded from running texts (Schulman, Castellon, \& Seligman, 1989). Second, short story-like explanations may be asked for predefined situations, and the answers may be analyzed for patterns of explanations. Third, individuals may be asked to rate the possible causes of hypothetical, predefined situations along the basic dimensions (e.g., to what extent would the situation be stable in time). The most commonly used measure, the Attributional Style Questionnaire (ASQ; Peterson, Semmel, von Baeyer, Abramson, Metalsky, \& Seligman, 1982) applies the latter strategy providing six negative and six positive events and instructs the respondents to evaluate each situation on three seven point scales, asking whether the actual situation is due to something, to the person, or to others/the circumstances (internality), and whether the cause will be present in the future or not (stability) and does the cause influence other events as well or just the actual one (globality).

Despite its popularity, ASQ has also been criticized both for its psychometric and conceptual flaws. Conceptually, the rating of hypothesized situations on a set of highly abstract rating scales (in this case, "internality", "globality" and "stability" of the causes of the actual events) can be questioned because the underlying cognitive process is far from the everyday explanatory process itself. Usually, explanatory processes are largely automatic (Satpute \& Lieberman, 2006), follow the event immediately and involve everyday thoughts and words (Peterson, 1991). Consequently, more extended and focused explanatory style measures were suggested, considering both the quantity of the provided situations (Travers, Creed, \& Morrissey, 2015) and their thematic focus; for example in academic situations (Peterson \& Barrett, 1987) and in work settings (Proudfoot et al., 2001). These scales use the methodology of ASQ but apply other situational vignettes that are fitted to the aim of the questionnaire. However, these measures also rely on abstract attributions, which may raise questions on the ecological validity of the method.

\section{Measurement of an Optimistic Mindset with a Situational Judgment Approach}

The formulation of a theory on explanatory style attempted to give an account on everyday attributions to positive and negative events. Content analysis of spontaneous verbal reactions to situational cues is consistent with this original tenet (Peterson, Schulman, Castellon, \& Seligman, 1992), however, this procedure is relatively time consuming. There is an alternative approach to assessing ecologically valid reactions to real life situations in a more effective way, i.e. the situational judgment test approach.

Situational judgment tests (SJTs) were typically developed and applied in the domain of personnel psychology and assessment in the last 25 years (c.f., Campion, Ployhart, \& MacKenzie, 2014; Motowidlo, Dunnette, \& Carter, 1990). Most SJTs target the procedural knowledge of the individual in real life situa- 
tions, i.e. the "how" of his/her reactions, responses and attitudes. Methodologically, situational judgment tests usually present descriptions or pictorial depictions of relevant situations and ask respondents to make choices among possible realistic responses (Weekley \& Ployhart, 2006). Scoring follows a priori (e.g., expert) ratings of the appropriateness of a given response option. It was shown that SJT scores were valid predictors for long term success and performance (Lievens \& Sackett, 2012). Therefore, we considered the SJT based approach in our measuring of the explanatory style of the individuals. Since spontaneous causal explanations can be found in a wide range of written and spoken texts as well as in patterns of everyday thinking, there is a possibility to approach these explanations by modeling and assessing realistic responses to positive and negative situations.

\section{Development of the MQ Test}

A scale development was performed in several consecutive steps and started as early as 2005 . Originally, a group of experts (psychologists and trainers) created an original 36-item version based on the literature review of preliminary work with the learned optimism concept and the corresponding training experiences. A consecutive exploratory period provided enough data to revise the original version in 2011 and the preliminary results were used to further refine the items of the MQ Test. The present study provides information on the latest version of the test.

The MQ Test as a measure of optimistic mindset was designed to have a series of distinctive features that make it unique among the explanatory style questionnaires. First, it refers to both personal life and work life situations in a balanced quantity. Second, its measurement approach follows the SJT approach by offering real life thinking patterns as responses instead of abstract evaluative categories as in many of the above reviewed explanatory style questionnaires. Finally, the development of the MQ Test aimed at fitting well in the Hungarian and in a broader sense European culture as well, both through the depicted situations and the provided reaction alternatives.

The MQ Test consists of 36 items, each of them providing a real life situation as it would be experienced by the respondent and two potential reactions in the form of inner thoughts (see Figure 1 for sample item format). Respondents are instructed to imagine the situation as if it had just happened to them and to rate the two provided reactions as extremes of a 10-point scale according to their relative preference to react. The provided 10-point scale does not contain numerical information on the meaning of the opposite extremes, but they are formulated to represent an optimistic and a pessimistic way of thinking as a reaction to the situation. Every provided pair of reactions implicitly captures one aspect of the explanatory styles, i.e., they are worded to imply explanations for either stability, globality, or internality of the causes.

Among the 36 items there are 18 positive and 18 negative situations; 18 workplace and 18 personal life situations. 12 items represent each of the explanation dimensions. Thus, a 2 (positive, $\mathrm{P}$ vs. negative, $\mathrm{N}$ situations) by 2 (workplace/personal situations) by 3 (S, G and I reactions) matrix of items sets up the MQ Test and each 12 sub-dimensions is represented by 3 items $^{1}$. Since previous analyses showed that workplace and personal life situations did not discriminate between responses, six subscales are used in the subsequent analyses. Sample items are presented in Table 1.

\footnotetext{
${ }^{1}$ In the original MQ Test terminology, E (Endurance), $\mathrm{G}$ (Generalization) and $\mathrm{O}$ (Origin) dimension labels were used for S (Stability), G (Globality) and I (Internality) dimensions, respectively. However, for the sake of clarity, we applied the more generally used terminology in this article.
} 


\begin{tabular}{|c|c|c|c|c|c|c|}
\hline \multicolumn{7}{|c|}{ You receive a new assignment that you really enjoy. } \\
\hline $\begin{array}{l}\text { I enjoy it because } \\
\text { I'm really good at this! }\end{array}$ & & & & & $\begin{array}{l}\text { I er } \\
\text { an in }\end{array}$ & $\begin{array}{l}\text { because } \\
\text { ng task. }\end{array}$ \\
\hline $\mathrm{O} \quad \mathrm{O}$ & $\mathrm{O}$ & $\mathrm{O}$ & $\mathrm{O}$ & $\mathrm{O}$ & $\mathrm{O}$ & $\mathrm{O}$ \\
\hline
\end{tabular}

Note. In this case, agreement with the left extreme scores 10 and the right extreme scores 1.

All other options score between 1 and 10 according to the actual response.

Figure 1 Sample item and response format

Table 1 Sample items (situations and reaction alternatives provided for the respondents) and scoring of the MQ subscales

\begin{tabular}{|c|c|c|c|}
\hline Subscale & Situation & Reaction alternatives & Scoring \\
\hline \multirow{2}{*}{ PS } & \multirow{2}{*}{$\begin{array}{l}\text { You get the necessary information } \\
\text { from your busy boss in just a } \\
\text { couple of minutes. }\end{array}$} & $\begin{array}{l}\text { I always succeed in contacting } \\
\text { people. }\end{array}$ & 10 \\
\hline & & $\begin{array}{l}\text { Exceptional, I contacted her at a } \\
\text { good moment. }\end{array}$ & 1 \\
\hline \multirow{2}{*}{ NS } & \multirow{2}{*}{$\begin{array}{l}\text { The printer breaks down when you } \\
\text { are busy printing a scheduled } \\
\text { document. }\end{array}$} & Something always goes wrong. & 1 \\
\hline & & I have problems today. & 10 \\
\hline \multirow{2}{*}{ PG } & \multirow{2}{*}{$\begin{array}{l}\text { You quickly make up the lag after } \\
\text { your two day leave. }\end{array}$} & I am usually quick. & 10 \\
\hline & & $\begin{array}{l}\text { I work more concentrated when } \\
\text { lagging behind. }\end{array}$ & 1 \\
\hline \multirow{2}{*}{ NG } & \multirow{2}{*}{$\begin{array}{l}\text { You have to cancel your evening } \\
\text { because your partner gets sick. }\end{array}$} & $\begin{array}{l}\text { All of our plans are always } \\
\text { cancelled. }\end{array}$ & 1 \\
\hline & & $\begin{array}{l}\text { Still we may have time with each } \\
\text { other. }\end{array}$ & 10 \\
\hline \multirow{2}{*}{ PI } & \multirow{2}{*}{$\begin{array}{l}\text { You are assigned a new task that } \\
\text { you enjoy a lot. }\end{array}$} & Because I am good at it. & 10 \\
\hline & & Because the task is interesting. & 1 \\
\hline \multirow{2}{*}{ NI } & \multirow{2}{*}{$\begin{array}{l}\text { You scraped your car in a crowded } \\
\text { parking lot. }\end{array}$} & I was clumsy. & 1 \\
\hline & & The place was tight. & 10 \\
\hline
\end{tabular}

Note. Extreme scores are assigned with total agreement with one of the alternatives. A 10-grade scale was used to assess the relative strength of the agreement (see also Figure 1). Higher score means more optimistic explanatory style. 
Scoring of the items corresponds to the underlying theoretical assumptions while it was being refined and examined by a continuous teamwork of professionals. For example, in a PS item the situation is positive (success in getting the information, see Table 1) and the two reactions highlight the temporal alternatives of thinking (extended or momentary) where a temporally extended reaction counts as more optimistic. In contrast, in a NS item where the situation is negative, the optimistic reaction type is the one that refers to the transitory aspects of the experience. Actual scoring occurs according to the rating of the relative possibility of the two extremes and it may range between 1 and 10. Scores of the six items of each subscale are summed up to form a subscale score. Moreover, subscale scores may be further summed up to form scores for negative or positive situations, or scores for $\mathrm{S}, \mathrm{G}$ and I dimensions, or else a general optimism (vs. pessimism) score as a sum of all subscales (i.e., all of the 36 items).

\section{The Present Study}

The aim of the present study is twofold. First, we present the results of the first validation study with the MQ Test. Based on preliminary results it was extensively used as an assessment tool; however it has not been systematically tested for its psychometric properties. To reach this end we explore its internal structure, compare several indices of reliability (alpha coefficient, test-retest correlation and ipsative stability) and develop a psychometrically sound test version along with its convergent and divergent validity. Second, we present data on the associations between facets of explanatory style and a series of widely used indicators of personal well-being and positive functioning. We hypothesized that higher optimism as measured by the MQ Test would positively relate to satisfaction with life, self-esteem and self- efficacy. However, we did not form any specific hypotheses regarding how the sub-dimensions of the MQ Test would predict well-being, leaving this aspect of the study open for exploration.

\section{Method}

\section{Samples and Procedure}

\section{Sample 1, community assessment}

In an online survey we collected data using snowball methodology and online advertisement for reaching the potential participants. The survey was provided in Hungarian and all participants were of Hungarian nationality. Eligibility for participation was predefined as having a full time equivalent job and being older than 18 years (adults). Subjects participated voluntarily and anonymously and received no payment for their participation. Respondents who did not meet the inclusion criteria (typically students) were omitted from the analysis. In sum, 459 Hungarian employees participated in the study, 139 male and 319 female $(30.3 \%$, mean age $45.4 \pm 15.4$ years and $69.5 \%$, mean age $44.3 \pm 12.0$ years, respectively, with 1 case, $0.2 \%$, missing). Most of the sample graduated from higher education $(\mathrm{N}=329,71.7 \%), 26$ respondents $(5.7 \%)$ completed primary school and 103 respondents had a high school degree $(22.4 \%$, 1 case, $0.2 \%$, missing). Approximately half of the sample $(\mathrm{N}=230,50.2 \%)$ was employed as operative employees, while 217 respondents (47.2\%) worked as a manager, among them 92 in low-level management, 92 in mid-level management and 33 in top management positions. 12 respondents $(2.6 \%)$ did not give a position.

\section{Sample 2, test-retest assessment}

Using a sample of employees in five medium to large sized Hungarian companies, we col- 
lected data from 43 male $(33.3 \%$, mean age 41.5 \pm 9.9 years) and 86 female $(66.7 \%$, mean age $38.6 \pm 8.4$ years) Hungarian speaking respondents at two different time points. Assessment was performed through the same online survey system as in Sample 1. Anonymity and confidentiality were guaranteed for the respondents. The mean of the days passed between the two assessments was 14.14 days $(S D=$ 8.87 days).

\section{Measures}

\section{Sample 1, community assessment}

$M Q$ Test. The 36-item version of the MQ Test was used, where each of the 36 items depicted everyday private and work situations and provided two different ways of inner response/thoughts as an immediate reaction to the situation. Respondents were asked to imagine the provided situations and indicate on a 10-point scale which answer they endorsed more. During the assessment there was no hint for scoring of the items. Item scoring is based on an a priori classification of the reactions, always assigning 1 to the less optimistic reaction and 10 to the more optimistic reaction (see more detailed description above). Detailed psychometric analysis is given below.

Rosenberg Self-Esteem Scale (RSES). RSES (Rosenberg, 1965; Sallay, Martos, Földvári, Szabó, \& Ittzés, 2014) is a broadly used 10-item measure of general self-esteem. The Likert-type response format ranges from 1 (strongly disagree) to 4 (strongly agree), a sample item is "I take a positive attitude toward myself'. Internal consistency was excellent in the sample ( $\alpha$ $=0.905$ ).

Satisfaction with Life Scale (SWLS). SWLS (Diener, Emmons, Larsen, \& Griffin, 1985; Martos, Sallay, Désfalvi, Szabó, \& Ittzés, 2014) is a 5 -item scale for assessing the cognitive component of subjective well-being, i.e., satisfaction with life. General statements like "I am satisfied with my life." are scored on a 7-point Likert-type scale $(1=$ strongly disagree, $7=$ strongly agree). Internal consistency was satisfactory in the sample $(\alpha=0.882)$.

Self-Efficacy Scale (SES). SES (Schwarzer \& Jerusalem, 1995b; Kopp, Schwarzer, \& Jerusalem, 1995) assesses the efficacy beliefs of the individuals via items like "It is easy for me to stick to my aims and accomplish my goals." Statements were evaluated on a 7-point Likerttype scale $(1=$ Not at all true, $7=$ Exactly true $)$. Internal consistency was good in the sample $(\alpha=0.885)$.

Adult Hope Scale (AHS). AHS (Snyder, Harris et al., 1991; Martos, Lakatos, \& Tóth-Vajna, 2014) captures hope as the perceived capability to derive pathways to desired goals (Pathways subscale, 4 items, sample item "There are lots of ways around any problem.") and an agentic thinking style in using these pathways (Agency subscale, 4 items, sample item "I energetically pursue my goals."). Responses were requested on a Likert-type scale ranging from 1 (Definitely False) to 7 (Definitely True). Internal consistency was satisfactory in the sample $(\alpha=0.836$ and 0.806 for Pathways and Agency subscales, respectively).

Life Orientation Test Revised (LOT-R). Dispositional optimism was measured by LOT-R (Scheier, Carver, \& Bridges, 1994; Bérdi \& Köteles, 2010). Statements refer to a general optimistic (vs. pessimistic) regard of life (sample item is "In uncertain times, I usually expect the best.") and are scored on a 7-point Likert-type scale. Internal consistency was satisfactory in the sample $(\alpha=0.873)$.

\section{Sample 2, test-retest assessment}

In both time points the 36-item version of the MQ Test was assessed. 
Table 2 Reliability indices of the MQ subscales

\begin{tabular}{|c|c|c|c|c|c|c|}
\hline \multicolumn{4}{|c|}{ Alpha } & \multirow{2}{*}{$\begin{array}{l}\text { Test-retest } \\
\text { correlations } \\
\text { Sample } 2\end{array}$} & \multicolumn{2}{|c|}{$\begin{array}{l}\text { Ipsative stability }^{\mathrm{a}} \\
\mathrm{T} 1-\mathrm{T} 2\end{array}$} \\
\hline Scale & Sample 1 & $\begin{array}{l}\text { Sample } 2 \\
\text { T1 }\end{array}$ & $\begin{array}{l}\text { Sample } 2 \\
\text { T2 }\end{array}$ & & Mean & $S D$ \\
\hline Nr of S's & 459 & 129 & 129 & 129 & 129 & \\
\hline PS & 0.563 & 0.561 & 0.673 & 0.770 & 0.571 & 0.417 \\
\hline NS & 0.600 & 0.611 & 0.714 & 0.819 & 0.552 & 0.394 \\
\hline S & 0.633 & 0.673 & 0.745 & 0.850 & 0.588 & 0.362 \\
\hline PG & 0.447 & 0.521 & 0.582 & 0.756 & 0.571 & 0.369 \\
\hline NG & 0.648 & 0.664 & 0.803 & 0.787 & 0.558 & 0.410 \\
\hline G & 0.612 & 0.700 & 0.748 & 0.812 & 0.683 & 0.317 \\
\hline PI & 0.504 & 0.467 & 0.597 & 0.693 & 0.600 & 0.255 \\
\hline NI & 0.361 & 0.308 & 0.423 & 0.779 & 0.699 & 0.217 \\
\hline I & 0.394 & 0.462 & 0.518 & 0.766 & 0.622 & 0.272 \\
\hline $\mathrm{P}$ & 0.731 & 0.771 & 0.837 & 0.823 & 0.595 & 0.274 \\
\hline $\mathrm{N}$ & 0.689 & 0.705 & 0.802 & 0.834 & 0.674 & 0.252 \\
\hline $\begin{array}{l}\text { Total MQ } \\
\text { score }\end{array}$ & 0.748 & 0.827 & 0.870 & 0.866 & 0.667 & 0.187 \\
\hline
\end{tabular}

Note. ${ }^{\text {a }}$ For the computation method of ipsative stability see text.

$\mathrm{P}=$ positive situations, $\mathrm{N}=$ negative situations, $\mathrm{S}=$ stability explanations, $\mathrm{G}=$ Globality explanations, I = Internality explanations

$\mathrm{PS}=\mathrm{S}$ explanations for $\mathrm{P}$ situations, $\mathrm{NS}=\mathrm{S}$ explanations for $\mathrm{N}$ situations, $\mathrm{PG}=\mathrm{G}$

explanations for $\mathrm{P}$ situations, $\mathrm{NG}=\mathrm{G}$ explanations for $\mathrm{N}$ situations, $\mathrm{PI}=\mathrm{I}$ explanations for $\mathrm{P}$ situations, $\mathrm{NI}=\mathrm{I}$ explanations for $\mathrm{N}$ situations

Ipsative stability is calculated as averaged individual Pearson correlation coefficients for the specific item sets between T1 and T2 assessment.

\section{Results}

\section{Overview of the Analytic Process}

In the first step we computed classical psychometric indices for the original item pool and subscales and ran a series of explorative factor analyses to uncover the internal structure of the measure. Based on these results we proposed a short research version of the MQ Test (SMQ Test) and tested its structure via confirmative factor analysis (CFA). Consecutively, we tested the relationship of SMQ Test dimensions and several validation constructs by structural equation modeling (SEM).

\section{Reliability of the MQ Test Scales}

As a next step we calculated a series of reliability indices for the subscales and summarized scales of the MQ Test ${ }^{2}$. We tested all theoretically relevant subscales using internal consistency estimates (alpha coefficients) in both samples and test-retest stability and ipsative stability estimates in test-retest sample.

\footnotetext{
${ }^{2}$ Details of the item level descriptive analyses and correlations are available from the corresponding author on request.
} 


\section{Alpha Coefficients}

Alphas were typically low to medium in magnitude with NI subscale ranging from 0.361 to 0.423 as the lowest and with NG subscale ranging from 0.648 to 0.803 as the highest values (Table 2). Summed scales for positive and negative situations as well as the total MQ score showed acceptable to excellent internal consistency (alphas between 0.689 and 0.870 ).

\section{Test-Retest Correlations}

Test-retest correlation coefficients were satisfactorily high and significant with Pearson $r \mathrm{~s}$ ranging from 0.693 to 0.866 (see Table 2 for details). Pooled $95 \%$ confidence intervals ranged from 0.591 to 0.904 . When we partitioned Sample 2 into four equal groups according to the actual time interval, the only pattern that emerged was that in the shortest interval quartile the correlations were somewhat higher than in the other quartiles. However, even in these cases the correlations were satisfactorily high. Additionally, we compared T1 and T2 scores using paired samples t-test. None of the pairs of scale scores and subscale scores showed significant difference within the assessed time period. These results mean that the scores of the scales and subscales are stable in a relatively short time period provided that no interventions had been undertaken.

\section{Ipsative Stability}

Using the same test-retest sample (Sample 2) we assessed ipsative stability of the responses by the following procedure. Individual item scores of Time 1 and Time 2 were correlated for each respondent, first for the six subscales separately (one Pearson correlation coefficient for each respondent with the $6+6$ PS Time 1 and PS Time 2 item pairs, and then the same for NS, PG, NG, PI and NI items, respectively), second for $\mathrm{P}$ and $\mathrm{N}$ items, third for $\mathrm{S}, \mathrm{G}$ and I items, and fourth for the whole item set of the MQ. These correlations represent the ipsative stability of the responses of a certain item set in case of a specific respondent. Additionally, we computed an average of the six subscale correlation coefficients for each respondent.

Individual Pearson correlation coefficients and the additionally averaged coefficient of the six subscales were then averaged through the 129 respondents (see Table 2). Averaged correlation coefficients are above 0.55 and some of them are close to 0.70 . That means that there is a relatively high stability in the way individuals respond to the specific situational cues. Moreover, average of the six subscale correlation coefficients was also high (mean $=0.589, S D=$ 0.194 ) indicating that there is also a considerable amount of coherence of the response styles between the subscales.

\section{Structural Analysis}

To explore the structure of the MQ Test we conducted a series of exploratory principal components analysis (PCA). In an initial components extraction, 11 components with an eigenvalue above 1.0 emerged, explaining $51.55 \%$ of the variance. Inspection of the scree plot pointed to a potential two or three components solution. We tested the two, three and four components solutions against the criterion of interpretability. Using direct oblimin rotation, two components solution presented two general components that were mostly loaded by items with positive and negative situations. In the three components solution NI items loaded mostly on the third component, although with relatively low component loadings. The four component solution did not add any interpretable differences to the previous patterns ${ }^{3}$. We

\footnotetext{
${ }^{3}$ Details of the principal component analyses are available from the corresponding author on request.
} 
found that two robust and well interpretable components emerged that represented the positive and negative situations. Therefore we used this solution for the next steps.

To build a psychometrically sound test version of the MQ Test we conducted confirmative factor analysis (CFA) and tried to fit the most interpretable item patterns to a theoretically meaningful model. Based on the results of PCA we selected 14 items of the original MQ Test with the highest loadings ( 0.4 and above) on one of the components of the two component solutions. Thus, we used 7 items with positive and 7 items with negative situations in the subsequent analysis, comprising the Short MQ Test. First we tested and compared two models by CFA(Maximum Likelihood estimation). The first model consisted of one latent variable rep- resenting all items. The second model consisted of two correlating latent variables representing the positive and negative situations, respectively. The fit indices of the second model with two correlated latent factor $($ Chi square $=149.74$, $d f=75, p<0.001$, chi square $/ d f=2.00, \mathrm{NFI}=$ $0.87, \mathrm{TLI}=0.92 . \mathrm{CFI}=0.93$, RMSEA $=0.047$, CI $90 \%=0.036-0.057$ ) not only outperformed the first model (Chi square $=366.43, d f=77, p<$ 0.001 , chi square $/ d f=4.76, \mathrm{NFI}=0.69, \mathrm{TLI}=$ $0.68, \mathrm{CFI}=.73, \mathrm{RMSEA}=0.091, \mathrm{CI} 90 \%=0.081$ -0.100 ) but the fit indices themselves showed acceptable fit of the second model (Hu \& Bentler, 1999). Therefore, we accepted that two intercorrelated but distinct dimensions represent the optimistic mindset in positive as well as in negative situations. Table 3 presents the standardized coefficients of the final model.

Table 3 Coefficients of the Short MQ Test items in confirmative factor analysis

\begin{tabular}{|c|c|c|c|}
\hline & \multicolumn{3}{|c|}{ Latent factors } \\
\hline & & 1 & 2 \\
\hline PS & $\mathrm{mq3}$ & 0.62 & \\
\hline PG & mq9 & 0.34 & \\
\hline PS & mq15 & 0.49 & \\
\hline PG & $\operatorname{mq} 24$ & 0.43 & \\
\hline PS & $\operatorname{mq} 25$ & 0.46 & \\
\hline PG & mq28 & 0.50 & \\
\hline PS & mq35 & 0.53 & \\
\hline NG & mq7 & & 0.56 \\
\hline NS & mq14 & & 0.50 \\
\hline NS & mq21 & & 0.49 \\
\hline NS & $\operatorname{mq} 22$ & & 0.67 \\
\hline NS & mq31 & & 0.52 \\
\hline NG & mq32 & & 0.69 \\
\hline NG & mq34 & & 0.54 \\
\hline $\begin{array}{l}\text { Intercorrelation between } \\
\text { the latent factors } 1\end{array}$ & & 0.46 & \\
\hline \multicolumn{4}{|c|}{$\begin{array}{l}\text { Note. One additional covariance was included between error terms of item } 9 \text { and } 25 \text { due to } \\
\text { similar situational cue. } \\
\mathrm{P}=\text { positive situations, } \mathrm{N}=\text { negative situations, } \mathrm{S}=\text { stability explanations, } \mathrm{G}=\text { Globality } \\
\text { explanations, } \mathrm{PS}=\mathrm{S} \text { explanations for } \mathrm{P} \text { situations, } \mathrm{NS}=\mathrm{S} \text { explanations for } \mathrm{N} \text { situations, } \\
\mathrm{PG}=\mathrm{G} \text { explanations for } \mathrm{P} \text { situations, } \mathrm{NG}=\mathrm{G} \text { explanations for } \mathrm{N} \text { situations } \\
{ }^{1} \text { standardized covariance estimate }\end{array}$} \\
\hline
\end{tabular}


We computed the $\mathrm{P}$ and $\mathrm{N}$ subscales and the total SMQ score of the Short MQ Test. The scales showed acceptable to adequate internal consistency $(0.687,0.767$ and 0.763, for SMQ-P, SMQ-N and SMQ Total, respectively). Additionally, we computed Pearson correlation coefficients between original and revised scales. Coefficients yielded $0.854,0.821$ and 0.871 for the three scales of $\mathrm{P}, \mathrm{N}$ and Total scores, respectively.

\section{CFA of the Validation Constructs}

Based on preliminary research reports we tested the structure of the validations constructs by a series of separate CFAs. In case of LOT-R, two correlated latent factors were assumed that corresponded to Optimism and Pessimism (Bérdi et al., 2010; Herzberg, Glaesmer, $\&$ Hoyer, 2006). The bifactor structure of the AHS was tested according to the results of Martos and colleagues (2014) with one General Hope factor and two factors for Pathway and Agency dimensions. Similarly, the bifactor structure of RSES was assumed but only the General Self-esteem factor was interpreted and the other two factors represented the method variance of positively and negatively worded items (cf. Sallay et al., 2014). In cases of SWLS and SES one latent factor was defined for each measure (cf. Martos et al., 2014). Detailed results of the fit indices are summarized in Table 4. It is evident that all measures fitted the theoretically meaningful models satisfactorily.

\section{Convergent and Predictive Validity of the SMQ Dimensions}

In the next step we built five SEM models to estimate the correlation coefficients of SMQ dimensions $\mathrm{P}$ and $\mathrm{N}$ and each of the validation constructs (see Table 5). Convergent validity was assessed as a correlation with OptimismPessimism and General Hope constructs. SMQ-N was closest to dispositional optimism (standardized covariance coefficient $=0.626$, $p<0.001)$ and had an inverse and somewhat weaker relation to pessimism (-0.490). In contrast, SMQ-P seems to capture relatively different aspect of optimism than dimensions of LOT-R although the correlations are in the predictable directions ( 0.17 for optimism and -0.28 for pessimism, in both cases $p<0.01$ ). Both SMQ-P and SMQ-N had weak-medium associations with dispositional hope as captured by AHS (0.346 and 0.460, $p<0.001$, respectively).

Predictive validity was tested for measures of positive psychological functioning: self-es-

Table 4 Confirmative factor analyses of the validation measures

\begin{tabular}{|c|c|c|c|c|c|c|c|c|c|c|}
\hline Measure & Model description & Reference & Chi sq. & $d f$. & $p$ & Chi sq./df & NFI & TLI & CFI & RMSEA \\
\hline LOT-R & two correlated factor & Herzberg et al. (2006) & 18.24 & 8 & 0.020 & 2.28 & 0.98 & 0.98 & 0.99 & 0.053 \\
\hline AHS & $\begin{array}{l}\text { bifactorial model: one general } \\
\text { hope factor and two factors for } \\
\text { Pathways and Agency items }\end{array}$ & Martos et al. (2014) & 33.20 & 12 & 0.001 & 2.77 & 0.98 & 0.97 & 0.99 & 0.062 \\
\hline SES & one latent factor ${ }^{1}$ & & 70.12 & 30 & $<0.001$ & 2.34 & 0.96 & 0.97 & 0.98 & 0.054 \\
\hline SWLS & one latent factor ${ }^{1}$ & Martos et al. (2014) & 13.74 & 5 & 0.017 & 2.75 & 0.99 & 0.99 & 0.99 & 0.062 \\
\hline RSES & $\begin{array}{l}\text { bifactorial model: one self- } \\
\text { esteem factor and two method } \\
\text { factors for positive and } \\
\text { negative worded items }\end{array}$ & Sallay et al. (2014) & 62.86 & 24 & $<0.001$ & 2.62 & 0.96 & 0.97 & 0.98 & 0.059 \\
\hline
\end{tabular}

Note. LOT-R = Life Orientation Test Revised (optimism), AHS = Adult Hope Scale, SES = Self-Efficacy Scale, SWLS = Satisfaction with Life Scale, RSES = Rosenberg Self-Esteem Scale

${ }^{1}$ with additional covariances between error terms 
Table 5 Estimated correlation coefficients between MQS dimensions and constructs of positive functioning

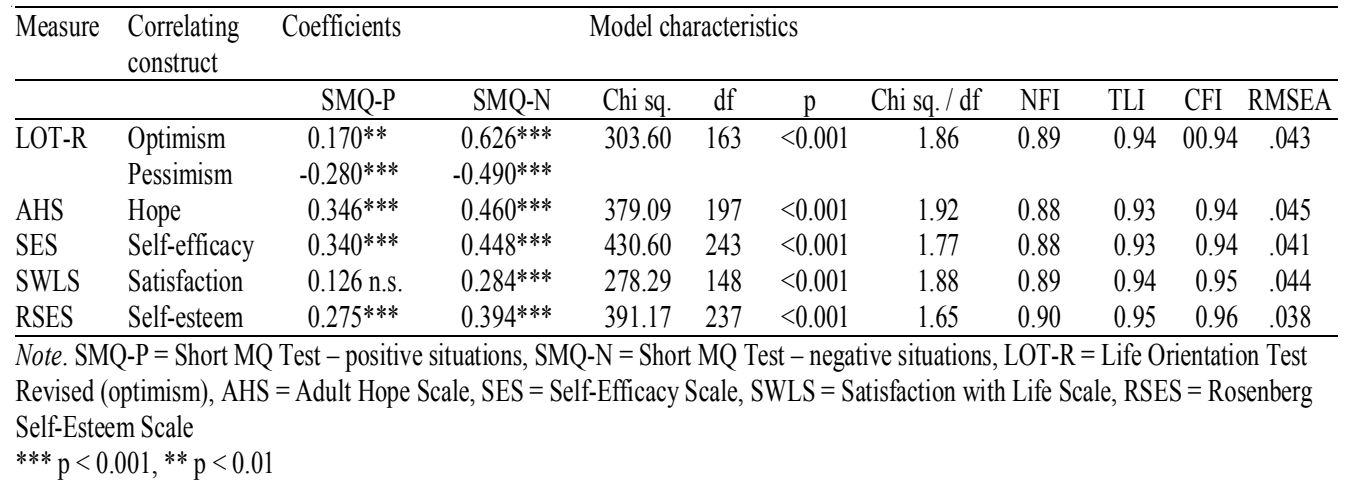

teem, satisfaction with life and self-efficacy. SMQ dimensions related differentially to these constructs: $\mathrm{N}$ dimension was in all three cases the stronger association than $\mathrm{P}$ dimension, while satisfaction with life did not relate to SMQ-P significantly. Among the constructs the associations were stronger for self-efficacy and self-esteem (between 0.275 and $0.448, p<0.001$ ), which are more about functioning of the self, and weaker (if significant at all) for satisfaction, which is considered as a subjective experience $(0.284, p<0.001)$.

\section{Discussion}

We presented the first study to test the psychometric properties as well as the theoretical potential of the newly developed MQ Test in samples of Hungarian employees. Below we summarize the most comprehensive findings of our first general validation study of the MQ Test, wherein we analyze its strengths and its features that are still to be developed.

While the MQ Test refers to a firm theoretical background of explanatory styles and the resulting optimistic vs. pessimistic mindset (Seligman, 1991), it provides a new way for mea- suring this mindset. According to the original theory, these processes have different roles in building an optimistic mindset depending on the primary positive or negative nature of the event. The MQ Test addresses this difference in its items (i.e., uses a balanced set of positive and negative events) and scoring (e.g., different scoring for generalized reactions to positive and negative events). The MQ Test has several features that are similar to other tests measuring optimistic explanatory style. It provides a series of real life situations, both positive and negative ones by nature, and asks for potential attributions for the event. However, unlike other tests, the response format does not rely on scaling of abstract categories (e.g., perceived "stability" of the event). Instead, it provides alternative descriptions of realistic inner thoughts that are developed to capture one dimension of the three dimensions of possible explanations with two extremes as alternatives. This procedure brings the test situation close to real life situations, thus its ecological validity is presumably higher than the previously designed scales with abstract ratings. In this way, the methodology of the MQ Test is similar to situational judgment tests (Campion et al., 
2014; Motowidlo et al., 1991) and many of its favorable but also unfavorable characteristics may be interpreted with regard to this basic characteristic.

First, while certain psychometric properties of the original MQ Test version were acceptable, detailed analyses found considerable limitations as well. Test-retest correlations of the MQ Test scales showed that the 2-3 week stability of the scales is satisfactorily high, although the time interval of the test-retest period varied considerably. Later investigations have to address the course of optimistic mindset with more rigor; however, we may expect that it would show substantial temporal stability given that the explanatory style is considered a traitlike personal characteristic (cf. Peterson \& Steen, 2009). Ipsative stability (i.e., the similarity of the profiles of individual responses between two time points) of the original scales was also acceptable, while internal consistency estimates (as measured by alpha coefficient) were generally in the low-medium range and were especially low for I scales. Remember that the low alpha coefficient is a common problem for measures where situations (e.g., descriptions or pictures) are used as clues, i.e., in situational judgment tests (c.f. Campion et al., 2014; Motowidlo et al., 1991).

Second, consistently with the limited internal consistency of the subscales, the structural validity of the initial MQ Test item set could not be verified in detail. In general, only two robust factors could be demonstrated by exploratory techniques: one for positive and one for negative events. In the subsequent scale development and analysis process and using the original MQ Test item pool we were able to distill a short 14-item version of the MQ Test (SMQ) with acceptable psychometric and structural properties. Two correlating latent factors with positive situations from one side and negative situations from the other side fitted the data well. This may indicate that the personal ex- planatory style of the respondents may be somewhat different for these two classes of situation. Moreover, our finding is in line with the great part of the psychometric research on explanatory style questionnaires (e.g., Ashforth \& Fugate, 2006; Liu \& Bates, 2014; Proudfoot et al., 2001; Smith, Caputi, \& Crittenden, 2013).

Third, we estimated the associations of the $\mathrm{P}$ and $\mathrm{N}$ dimensions of the SMQ Test with related constructs (optimism, hope) as well as indices of positive functioning (self-efficacy, self-esteem and satisfaction with life). Results showed adequate convergent validity of the SMQ dimensions. Optimistic attributions to negative situations seem to tap especially well into dispositional optimism as measured by LOT-R and adequately into dispositional pessimism and hope. In contrast, optimistic reactions to positive events related more explicitly to the construct of hope, showing again that $\mathrm{P}$ dimension represents a somewhat different kind of mindset than $\mathrm{N}$ dimension does. As a general remark we may note that the magnitude of the correlation coefficients were in the middle range, indicating that the constructs under scrutiny cannot be treated as identical.

Additionally, we used SMQ Test dimensions as correlates for constructs of positive functioning. The associations of $\mathrm{P}$ and $\mathrm{N}$ dimension were stronger for self-efficacy and self-esteem and weaker or not significant for satisfaction with life. We may interpret this pattern that the optimistic explanatory mindset - as measured by SMQ Test dimensions - comprises an integral part of the person's self system and represents an important way of social-cognitive information processing (cf. Mischel \& Shoda, 1995). At the same time, it may have consequences also for the subjective experience of the individual: a more optimistic mindset in negative situations may strengthen the personal capacity for resilience and thus may contribute to the appreciation of positive aspects of one's life, that is, life satisfaction. 
The predominance of the $\mathrm{N}$ dimension in the associations with other constructs is an unforeseen and interesting finding that merits later investigation. It may focus on the question whether the use of optimistic handling of negative situations as a source of positive experience and well-being is a culture specific or universal human phenomenon.

\section{Limitations}

Our study has certain limitations. First, the cross sectional nature of the main data does not allow causal explanations of the result. Second, snowball recruitment and self-report online responses may raise concerns about the validity of the answers. Third, although the procedure applies real life situations, the personal experience of the respondents with these situations may vary considerably and this may affect the validity of the results. This assumption needs further investigation in later assessments. Fourth, while results with the Short MQ Test are promising, further efforts need to be taken to develop the psychometric properties of the original MQ Test and to increase its precision. Finally, our samples consisted of exclusively Hungarian respondents. Cross-cultural validation of the results is an important challenge for future research with the MQ Test.

\section{Conclusions and Future Directions}

To our best knowledge our study with the MQ Test was the first attempt to develop and explore a measure for individual explanatory style using a situational judgment approach. We presented both the merits and weaknesses of the present version of this measure and it is clear that further efforts have to be made toward the psychometric refinement of it.

As we presented, alpha coefficients of the original subscales were found relatively low in comparison to widely suggested reference points. In this way, the original MQ Test presents a relatively common characteristic in situations judgment tests (Campion et al., 2014; Motowidlo et al., 1991).

In its present form, the Short MQ Test with two correlated $\mathrm{P}$ and $\mathrm{N}$ subscales may be regarded as a psychometrically fully acceptable construct that is suitable for scientific work as well. Distinctiveness of Stability, Generality and especially Internality judgments can be further elaborated in a revised version of the original MQ Test. Further refinements of the measurement's precision may help to disentangle subdimensions as well. Taking all the above mentioned limitations seriously, we still believe that there is considerable practical and theoretical potential in the application of the MQ Test. As an assessment tool it may be especially well suited for training programs because it provides feedback for individuals about the actual mindset toward negative and positive life events. This way it may also give a basis for the exploration and development of alternative ways of thinking about reasons and explanations.

\section{References}

Ashforth, B. E., \& Fugate, M. (2006). Attributional style in work settings: Development of a measure. Journal of Leadership and Organizational Studies, 12, 12-29.

Bérdi, M., \& Köteles, F. (2010). Az optimizmus mérése: Az Életszemlélet Teszt átdolgozott változatának (LOT-R) pszichometriai jellemzői hazai mintán. Magyar Pszichológiai Szemle, 65, 273-294.

Campion, M. C., Ployhart, R. E., \& MacKenzie, W. I. (2014). The state of research on situational judgment tests: A content analysis and directions for future research. Human Performance, 27, 283310 .

Diener, E., Emmons, E. R., Larsen, R. J., \& Griffin, S. (1985). The Satisfaction with Life Scale. Journal of Personality Assessment, 49, 71-75.

Herzberg, P. Y., Glaesmer, H., \& Hoyer, J. (2006). Separating optimism and pessimism: A robust psychometric analysis of the revised Life Orientation Test (LOT-R). Psychological Assessment, 18, 433438 . 
Hu, L., \& Bentler, P. M. (1999). Cutoff criteria for fit indexes in covariance structure analysis: Conventional criteria versus new alternatives. Structural Equation Modeling, 6, 1-55.

Kopp, M. S., Schwarzer, R., Jerusalem, M. (1995). Hungarian adaptation of the General Self-Efficacy Scale. Available from http://userpage.fu-berlin.de/ $\sim$ health/hungar.htm

Lievens, F., \& Sackett, P. R. (2012). The validity of interpersonal skills assessment via situational judgment tests for predicting academic success and job performance. Journal of Applied Psychology, 97 460-468.

Liu, C., \& Bates, T. C. (2014). The structure of attributional style: Cognitive styles and optimismpessimism bias in the Attributional Style Questionnaire. Personality and Individual Differences, 66, 79-85.

Martos, T., Sallay, V., Désfalvi, J., Szabó, T., \& Ittzés, A. (2014). Az Élettel való Elégedettség Skála magyar változatának (SWLS-H) pszichometriai jellemzői. Mentálhigiéné és Pszichoszomatika, 15, 289-303.

Martos, T., Lakatos, Cs., \& Tóth-Vajna, R. (2014). A Remény Skála magyar változatának (AHS-H) pszichometriai jellemzői. Mentálhigiéné és Pszichoszomatika, 15, 187-202.

Mischel, W., \& Shoda, Y. (1995). A cognitive-affective system theory of personality: Reconceptualizing situations, dispositions, dynamics, and invariance in personality structure. Psychological Review, 102, 246-268.

Motowidlo, S. J., Dunnette, M. D., \& Carter, G. W. (1990). An alternative selection procedure: The lowfidelity simulation. Journal of Applied Psychology, $75,640-647$

Peterson, C. (1991). The meaning and measurement of explanatory style. Psychological Inquiry, 2, 1 10 .

Peterson, C., \& Barrett, L. C. (1987). Explanatory style and academic performance among university freshmen. Journal of Personality and Social Psychology, 53, 603-607.

Peterson, C., Schulman, P., Castellon, C., \& Seligman, M. E. P. (1992). The explanatory style scoring manual. In C. P. Smith (Ed.). Motivation and personality: Handbook of thematic content analysis (pp. 383-392.). Cambridge: Cambridge University Press

Peterson, C., Semmel, A., von Baeyer, C., Abramson, L. Y., Metalsky, G. I., \& Seligman, M. E. P. (1982). The Attributional Style Questionnaire. Cognitive Therapy and Research, 6, 287-299.

Peterson, C., \& Seligman, M. E. P. (1984). Causal explanations as a risk factor for depression: Theory and evidence. Psychological Review, 91, 347-374.
Peterson, C., \& Steen, T. A. (2009). Optimistic explanatory style. In C. R. Snyder \& S. J. Lopez (Eds.), Oxford handbook of positive psychology (2nd ed., pp. 313-321). New York: Oxford University Press.

Proudfoot, J. G., Corr, P. J., Guest, D. E., \& Gray J. A. (2001). The development and evaluation of a scale to measure occupational attributional style in the financial services sector. Personality and Individual Differences, 30, 259-270.

Rosenberg, M. (1965). Society and the adolescent self-image. Princeton, NJ: Princeton University Press.

Sallay, V., Martos, T., Földvári, M., Szabó, T., \& Ittzés, A. (2014). A Rosenberg Önértékelés Skála (RSESH): Alternatív fordítás, strukturális invariancia és validitás. Mentálhigiéné és Pszichoszomatika, 15, 259-275.

Satpute, A. B., \& Lieberman, M. D. (2006). Integrating automatic and controlled processes into neurocognitive models of social cognition. Brain Research, 1079, 86-97.

Scheier, M. F., Carver, C. S., \& Bridges, M. W. (1994). Distinguishing optimism from neuroticism (and trait anxiety, self-mastery, and self-esteem): A re-evaluation of the Life Orientation Test. Journal of Personality and Social Psychology, 67, 1063-1078.

Schulman, P., Castellon, C., \& Seligman, M. E. P. (1989). Assessing explanatory style: The content analysis of verbatim explanations and the Attributional Style Questionnaire. Behaviour Research and Therapy, 27, 505-512.

Schwarzer, R., \& Jerusalem, M. (1995a). Optimistic self-beliefs as a resource factor in coping with stress. In S. E. Hobfoll \& M. W. de Vries (Eds.), Extreme stress and communities: Impact and intervention (pp. 159-177). Dordrecht: Kluwer Academic Publishing.

Schwarzer, R., \& Jerusalem, M. (1995b). Generalized Self-Efficacy Scale. In J. Weinman, S. Wright, \& M. Johnston (Eds.), Measures in health psychology: $A$ user's portfolio. Causal and control beliefs (pp. 3537). Windsor: NFER-NELSON.

Seligman, M. E. P. (1991). Learned optimism. New York: Knopf.

Smith P., Caputi, P., Crittenden, N. (2013). Measuring optimism in organizations: Development of a Workplace Explanatory Style Questionnaire. Journal of Happiness Studies, 14, 415-432.

Snyder, C. R., Harris, C., Anderson, J. R., Holleran, S. A., Irving, L. M., Sigmon, S. T., et al. (1991). The will and the ways: Development and validation of an individual differences measure of hope. Journal of Personality and Social Psychology, 60, 570585. 
Travers, K. M., Creed, P. A., \& Morrissey, S. (2015). The development and initial validation of a new scale to measure explanatory style. Personality and Individual Differences, 86, 1-6.
Weekley, J. A., \& Ployhart, R. E. (Eds.). (2006). Situational judgment tests: Theory, measurement, and application. Mahwah: Lawrence Erlbaum. 